${ }^{8}$ Owens ML, Maxwell JG, Goodnight J, Wolcott, MW. Discontinuance of immunosuppression in renal transplant patients. Arch Surg 1975 110: $1450-1$.

- Lokkegaard H, Thaysen JH. Permanent withdrawal of prednisolone in necro-kidney transplantation. Proc Eur Dial Transplant Assoc 1976;13: 216-22.

10 Turcotte JG, Dickerman RM, Harper ML. Minimum steroid requirements in the late post-transplant period. Transplant Proc 1975;7:83-8.

11 Anderton J, Fananapazir L, Eccleston M. Minimum steroid requirements in renal transplant patients monitored by urinary fibrin degradation products and complement. Proc Eur Dial Transplant Assoc 1976;14:34250.

12 Wilson CG, May CS, Paterson JW. Plasma prednisolone levels in man following administration in plain and enteric-coated forms. $\mathrm{Br} \mathcal{F} \mathrm{Clin}$ Pharmacol 1977;4:351-5.

13 Lee DAH, Taylor GM, Walker JG, James VHT. The effect of food and tablet formulation on plasma prednisolone levels following administration of enteric-coated tablets. Br f Clin Pharmacol 1979;7:523-8.

(Accepted 4 March 1980)

\title{
Anabolic effect of human parathyroid hormone fragment on trabecular bone in involutional osteoporosis: a multicentre trial
}

\author{
JONATHAN REEVE, PIERRE J MEUNIER, JOHN A PARSONS, MICHEL BERNAT, \\ OLAV L M BIJVOET, PHILIPPE COURPRON, CLAUDE EDOUARD, LESLIE KLENERMAN, \\ ROBERT M NEER, JEAN C RENIER, DAVID SLOVIK, F JON F E VISMANS, \\ JOHN T POTTS, JR
}

\section{Summary and conclusions}

After baseline studies, 21 patients with osteoporosis were treated with human parathyroid hormone fragment (PTH 1-34) given as once-daily subcutaneous injections for 6-24 months. The dose used did not cause hypercalcaemia even in the first few hours after injection. Calcium and phosphate balances improved in some patients, but there was no significant improvement in the group values. There were, however, substantial increases in iliac trabecular bone volume: the mean increase, confirmed by repeat blind measurements, was $70 \%$ above mean baseline volume. The new bone was histologically normal. Those patients who had the

Medical Research Council Clinical Research Centre, and Northwick

Park Hospital, Harrow, Middlesex HA1 3UJ

JONATHAN REEVE, DM, member of MRC clinical scientific staff

LESLIE KLENERMAN, $\mathrm{MCH}$, consultant orthopaedic surgeon

Laboratoire de Récherches sur l'Histodynamique Osseuse, University of Lyon, France 69

PIERRE J MEUNIER, MD, professeur de médecine

CLAUDE EDOUARD, D SC, research assistant

Francheville Hospital, Lyon, France 69

PHILIPPE COURPRON, MD, head of geriatric centre

Laboratory of Endocrine Physiology and Pharmacology, National Institute for Medical Research, London NW7

JOHN A PARSONS, BM, head of laboratory

Department of Clinical Rheumatology, Centre Hôpitalier et Universitaire d'Angers, 49036 Angers, France

MICHEL BERNAT, MD, assistant-chef de clinique (Dr Bernat died on 29 November 1979)

JEAN C RENIER, $M D$, professor

Department of Clinical Endocrinology, University Hospital, Leiden, Netherlands

OLAV L M BIJVOET, MD, professor

F JON F E VISMANS, MD, internist (present address: Elizabeth Hospital, Willamstad, Curaçao, Netherlands West Indies)

Harvard Medical School, and Massachusetts General Hospital, Boston, Massachusetts 02114, USA

ROBERT $M$ NEER, MD, associate professor of medicine

DAVID SLOVIK, MD, instructor in medicine

JOHN T POTTS, Jr, MD, professor of medicine largest increases in ${ }^{47} \mathrm{Ca}$-kinetic and histomorphometric indices of new bone formation showed the greatest increases in trabecular bone volume, suggesting that treatment with human parathyroid hormone fragment caused a dissociation between formation and resorption rates that was confined to trabecular bone.

Since vertebrae are four-fifths composed of trabecular bone, this hormone fragment may prove useful in treating patients with the crush fracture syndrome.

\section{Introduction}

The rate of renewal of the skeleton in most patients with osteoporosis is about 5\% yearly. ${ }^{12}$ Thus any treatment aimed at rapidly reversing a typical ${ }^{3} 20 \%$ relative deficit in bone mass must increase the rate of formation of new bone. We have reported that giving low doses of synthetic human parathyroid hormone fragment (PTH 1-34) daily for six months roughly doubles the bone formation rate. ${ }^{45}$ We report here further results from our multicentre study.

\section{Patients and methods}

Sixteen women aged 49 to 78 years (mean 63 ) and five men aged 52 to 61 years (mean 56) were studied. Each gave informed consent to participation in the trial in the manner approved by his or her local hospital ethical committee. All but one had at least one severe vertebral crush fracture (the mean number being five: the remaining patient had a history of fractures of long bones (table). No patient had received fluoride treatment or a prolonged course of glucocorticoid treatment. The only known precipitating cause for osteoporosis apart from a lack of oestrogen was thyrotoxicosis. This had occurred in one patient and had been successfully treated 35 years before the trial. At the time of acceptance into the study no patient had received pharmacological doses of any vitamin $\mathrm{D}$ preparation within two years, although one patient in Boston (case 21) was treated with vitamin $\mathrm{D}_{3} 50 \mathrm{mg}$ (2000 IU) daily for two years before entering the trial, and all the British patients (cases $1-8$ ) were given vitamin $D_{2}$ $12.5 \mathrm{mg}$ (500 IU) daily from three months before their baseline values were determined. These doses were maintained throughout the study.

The following indices were normal in all patients: liver function tests, age-corrected and size-corrected glomerular filtration rates, plasma calcium and phosphate concentrations, alkaline phosphatase 
activity, thyroxine and cortisol concentrations, 24-hour urinary calcium and hydroxyproline excretions, faecal fat excretion, and blood count. Three women (cases 21, 24, and 41) were given oestrogen replacement treatment for at least 10 months before entering the study and throughout it. The remaining 14 women were postmenopausal. One of the men (case 43) was given a course of testosterone preparations of the same dose throughout the study.

The degree of incapacity that each patient experienced was assessed before treatment and at the end of treatment on the following scale: 5-bedridden; 4-confined to bed, chair, or wheelchair; 3ambulatory but lying down more than 12 hours daily; 2-ordinary activities limited by pain; 1 -only strenuous activities limited by pain; $0-$ no activities limited by pain.

\section{KINETICS}

The schedule of preliminary investigations, the analytical methods, and the treatment protocol have been described. ${ }^{46}$ Before treatment started each patient was admitted for a full 18-day study of calcium, phosphorus, and magnesium balance on a constant diet. In all but four cases this was performed with a continuously administered chromium sesquioxide faecal marker to improve precision. A radiocalcium kinetic study was performed simultaneously to determine the accretion rate of calcium, which is an index of new bone formation. ${ }^{7}$ The bone resorption rate was calculated as the difference between the accretion rate and the calcium balance. Shortly before or immediately after the balance study an $8-\mathrm{mm}$ transiliac trephine biopsy of the iliac crest was performed, usually after double tetracycline labelling. ${ }^{8}$ The biopsy samples were all reviewed by one of us (PJM), and for the sake of consistency the histological results reported here are those obtained in his laboratory alone.

\section{HISTOMORPHOMETRY}

Fourteen non-consecutive undecalcified sections were used from each biopsy specimen, of which four were unstained $(20 \mu \mathrm{m})$ and used for measurement of the tetracycline labels, and 10 were stained $(8 \mu \mathrm{m})$-four by the method of Goldner, ${ }^{9}$ four by solochrome cyanine $R,{ }^{10}$ and two by toluidine blue. To estimate trabecular bone mass trabecular bone volume was measured as the percentage of the total space between the inner and outer cortices occupied by trabecular bone (including osteoid). ${ }^{811}$ Trabecular osteoid volume (VO) was measured as the percentage of trabecular bone volume occupied by osteoid. Bone resorption was estimated both by measuring surfaces showing evidence of osteoclastic resorption as a percentage of total trabecular bone surfaces and by counting osteoclasts (number seen $/ \mathrm{mm}^{2}$ in the total area between subcortical envelopes). Bone forming activity was estimated from the proportion of trabecular surface covered by osteoid (SO) and by the calcification rate, which was determined by measuring the mean distances between the two tetracycline labels. ${ }^{8}$ The thickness index of osteoid seams ${ }^{12}$ was computed as the ratio: $(\mathrm{VO} / \mathrm{SO}) \times 100$

The 10 earliest biopsy samples were taken after inadequate tetracycline labelling and processed in another laboratory in an embedding medium which made subsequent osteoclast counting difficult. The other cause of loss of data was fragmentation of some of the samples. Biopsy samples that were fragmented or that had lost their inner cortical plate and more than one-quarter of their trabeculae were not accepted for the measurement of trabecular bone volume.

\section{TREATMENT}

After the initial assessment each patient began treatment with human parathyroid hormone fragment. The initial daily dose of $100 \mu \mathrm{g}$ was given as a single subcutaneous injection. ${ }^{4}$ In the intravenous chick hypercalcaemia assay ${ }^{13}$ each $100 \mu \mathrm{g}$ dose of peptide from the first three batches had about the same activity as $500 \mathrm{U}$ of bovine parathyroid hormone (PTH 1-84). The fourth batch, however, proved one and a half times as potent, and three patients in Boston and one in London who had started treatment with it had their doses reduced (cases $8,21,22$, and 25 ). The weight of peptide needed to maintain a constant dose in subsequent batches was determined by bioassay using an early batch set aside as a standard and shown to be stable by accelerated degradation tests. This weight had fallen to $50 \mu \mathrm{g}$ daily by the end of the trial.

In 19 patients all the studies outlined above were repeated six months after the start of treatment, second biopsies being performed on the other iliac crest when treatment was stopped. The other two patients continued treatment for longer: one (case 22) was studied after six months on $740 \mathrm{U} /$ day and again six months later on a reduced dose of $500 \mathrm{U} /$ day; the other (case 21) was studied after 18 months on $740 \mathrm{U} /$ day and again six months later after reduction of the dose to $400 \mathrm{U} /$ day in the 19th month.

Cortical bone densitometry was performed using ${ }^{125} I$-absorptiometry at the junction of the proximal two-thirds of the radius with the distal third in 14 cases, ${ }^{14}$ and using ${ }^{241} \mathrm{Am}$-absorptiometry at the junction of the proximal four-fifths of the femur with the distal fifth in cases $1-8 .{ }^{15}$

\section{Results}

\section{CLINICAL FINDINGS}

No side effects of treatment were noted except transient redness and itching at the injection site in one patient. No qualitative or quantitative changes occurred in any of the formed elements of the blood in association with treatment.

As assessed clinically and by repeat radiography of the dorsal and lumbar spine only one patient suffered a further vertebral fracture during the six-month treatment period. She had earlier reported pain apparently related to this fracture during her baseline study.

Clinical and laboratory findings and results of bone biopsy before and (unless otherwise stated) six months after treatment with human parathyroid hormone fragment in 21 patients with osteoporosis. Dashes indicate results unsatisfactory or not obtained

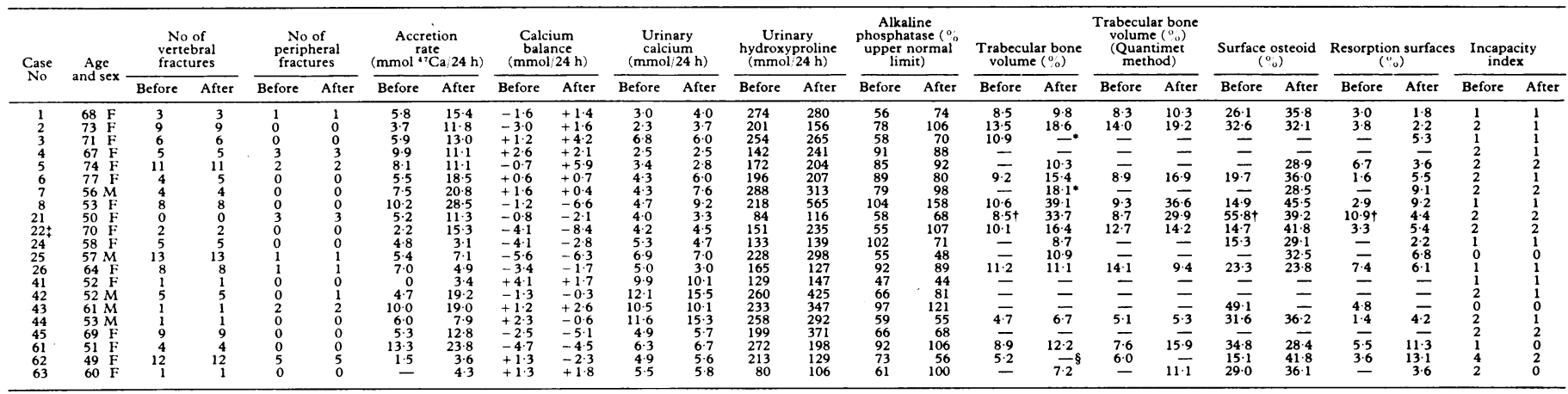


There was no significant loss of height over the treatment period (mean $-0 \cdot 2 \pm$ SEM $0 \cdot 2 \mathrm{~cm}$ ). Eight of the 21 patients felt sufficiently better to be regraded in the incapacity index, which therefore improved by a mean of $0.48 \pm 0 \cdot 15$ points. No patient became more incapacitated.

\section{BIOCHEMISTRY}

There were no significant changes in early-morning fasting plasma calcium and phosphate concentrations, but transient mild hypercalcaemia (rises of 0.3 to $0.4 \mathrm{mmol} / 1(1.2-1.6 \mathrm{mg} / 100 \mathrm{ml}$ ) above baseline 4-6 h after injection) was seen in four patients (cases 8,21, 22 , and 25), in each of whom it was abolished by reducing the dose of hormone fragment. The serum alkaline phosphatase activity increased by a mean of $15 \pm 7 \%$ of its baseline value $(p<0.05)$. Values in the table are expressed as a percentage of the local upper limit of normal because each centre measured it by a different method. The 24-hour urinary hydroxyproline excretion likewise increased by a mean of $26 \pm 10 \%$ of baseline $(p<0.02)$, although exceeding the normal range only in case 8. Urinary calcium excretion increased by a mean of $0.8 \mathrm{mmol} / 24 \mathrm{~h}(32.1 \mathrm{mg} / 24 \mathrm{~h})$, which was just significant $(\mathrm{p}<0.05)$, as was the mean increase in urinary phosphate excretion $(2.4 \mathrm{mmol} /$ $24 \mathrm{~h}(74 \mathrm{mg} / 24 \mathrm{~h})$ ).

\section{MINERAL BALANCE}

Despite considerable changes in individual values calcium balance did not change significantly in the group as a whole (baseline mean $-0.8 \mathrm{mmol} / 24 \mathrm{~h}(32.1 \mathrm{mg} / 24 \mathrm{~h})$, mean change $-0.1 \mathrm{mmol} / 24 \mathrm{~h}$ $(-4.0 \mathrm{mg} / 24 \mathrm{~h})$ ). Phosphate balances became more positive but this was only of borderline significance (baseline mean $+0.8 \mathrm{mmol} / 24 \mathrm{~h}$ $(+24.8 \mathrm{mg} / 24 \mathrm{~h})$, mean change $+2.9 \pm 1.7 \mathrm{mmol} / 24 \mathrm{~h}(+89.8 \pm$ $52.6 \mathrm{mg} / 24 \mathrm{~h}), \mathrm{p}<0 \cdot 1)$. Magnesium balances remained unchanged (baseline mean $-0.2 \mathrm{mmol} / 24 \mathrm{~h}(-4.9 \mathrm{mg} / 24 \mathrm{~h}$ ), mean change $-0.1 \pm 0.3 \mathrm{mmol} / 24 \mathrm{~h} \quad(-2.4 \pm 6.4 \mathrm{mg} / 24 \mathrm{~h}))$. True calcium absorption calculated as dietary calcium less faecal calcium corrected for its endogenous component did not change significantly (mean change $+0.2 \mathrm{mmol} / 24 \mathrm{~h}(+8.0 \mathrm{mg} / 24 \mathrm{~h})$ ).

The mean change in cortical bone density associated with treatment (as estimated by photon absorptiometry) was insignificantly different from zero $(-1 \cdot 7 \pm 1 \cdot 8 \%$ of baseline value).

\section{BONE FORMATION AND RESORPTION}

There were striking increases in the rate of new bone formation as measured by ${ }^{47} \mathrm{Ca}$-kinetics, the mean increase being $144 \pm 35 \%$ ( $<<0.001)$-equivalent to $7 \cdot 0 \pm 1 \cdot 3 \mathrm{mmol} / 24 \mathrm{~h}(280 \pm 52 \cdot 1 \mathrm{mg} / 24 \mathrm{~h})$. Trabecular osteoid surfaces also increased (mean increase $+11.8 \%$ from an initial mean value of $23.3 \%, p<0.02$ ), which in relative terms was not so much as the ${ }^{47} \mathrm{Ca}$-whole-body accretion rate. There were nine pairs of biopsy samples in which the tetracycline double label was well visualised and the calcification rate could be measured satisfactorily. The initial mean value of $630 \mathrm{~nm}$ /day increased by an insignificant $40 \mathrm{~nm} /$ day as a result of treatment, and since the thickness of osteoid seams was normal increased bone formation must have been due to an increase in forming surfaces. In no case was the calcification rate abnormal.

Histomorphometry of the iliac biopsy samples also showed considerable increases in trabecular bone volume in nine out of the ten pairs of biopsy samples satisfactory for this measurement (fig 1). The mean increase was from a mean volume of $9.3 \%$ to a mean volume of $17 \cdot 3 \%(+92 \%$ of baseline value). Because the data were skewed they were corrected for determining the level of significance by assessing a logarithmic transformation of the ratios of the values of the second biopsy samples to those of the first. The mean increase thus calculated was under $92 \%(+70 \%$ of baseline $)$. This increase was significant at the $1 \%$ level $(t=3.4$; these figures include those of case 62 , see footnote to table). The patient who did not respond to treatment was later found to have developed circulating antibodies to the injected hormone. Because of the importance of this observation the biopsy samples were re-examined blind by one of us (PC) using a Quantimet image-analysing computer, which yielded similar results (table).

The striking increases in accretion rate and bone forming surfaces were accompanied by increases in resorption surfaces, from a mean
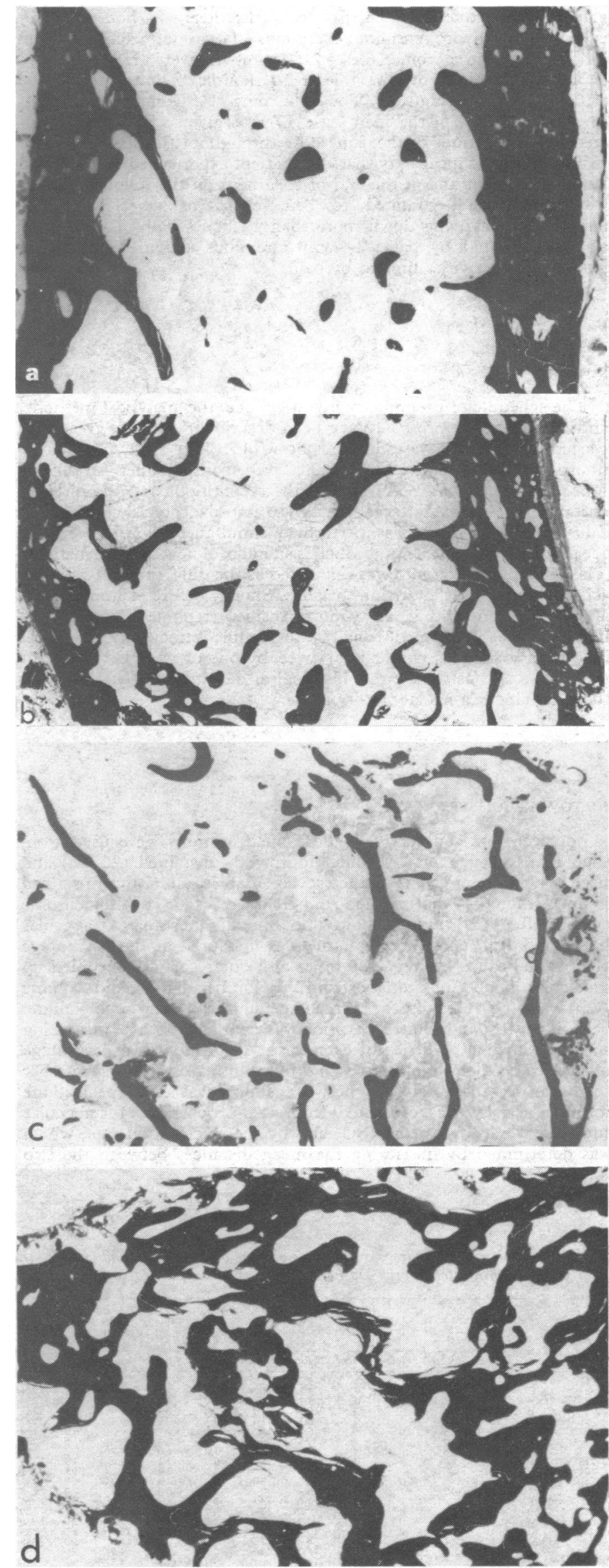

FIG 1-Two pairs of biopsy samples from trabecular bone (original magnification $\times 12 \cdot 5$ ).

(a) In case 6 before treatment, and (b) after treatment. Mean increase in trabecular bone volume (from $9 \cdot 1 \%$ to $16.1 \%$ ) was typical of whole group.

(c) In case 8 before treatment, and (d) after treatment. Trabecular bone volume rose from $10.0 \%$ to $37.9 \%$ : above upper limit of normal. 
of $3.9 \%$ to a mean of $6.2 \%$. For technical reasons it was possible to count osteoclasts in only six pairs of biopsy samples. In all but one case their numbers increased. The seven technically adequate pretreatment biopsies yielded a mean osteoclast count of $0.19 \pm 0.05 / \mathrm{mm}^{2}$, and the 14 post-treatment biopsies yielded a mean value of $0.62 \pm$ $0 \cdot 14 / \mathrm{mm}^{2}(t=2 \cdot 89, \mathrm{p}<0 \cdot 02)$.

\section{Discussion}

The increases in trabecular bone volume in these patients treated with synthetic human parathyroid hormone fragment (PTH 1-34) resulted from the formation of new bone on the surface of existing trabeculae, which was shown on detailed examination to be fully mineralised and of normal lamellar texture. Vertebrae, which are normally more than threequarters composed of trabecular bone, are dependent for their resistance to compressive forces on their bone mineral content, ${ }^{16}$ and there appears to be greater loss of trabecular bone than cortical bone in osteoporosis. ${ }^{317} 18$ Hence the observed increases in trabecular bone volume produced by treatment with this hormone fragment might usefully increase the strength of the vertebrae in patients with axial osteoporosis.

Because of the relatively wide distribution of the values of the trabecular bone volumes at the time of the second biopsy we attempted to find a measured variable that would provide a predictor to the outcome of treatment, using the trabecular bone volume as the endpoint. A close relation was found between the ${ }^{47} \mathrm{Ca}$-accretion rate achieved before the end of treatment and final trabecular bone volume (fig 2). The

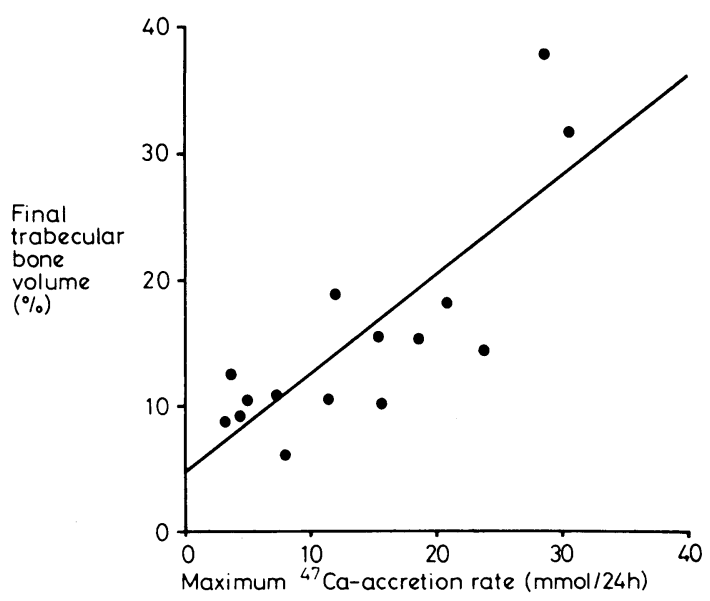

FIG 2-Relation between trabecular bone volume at time of final bone biopsy and maximum recorded ${ }^{47} \mathrm{Ca}$-accretion rate during period of treatment.

regression line shown was described by the equation: $\mathrm{Y}=$ $0.79 x+4.51 \pm 5.32 \quad(t=5.0, \quad \mathrm{p}<0.001, \quad \mathrm{r}=0.81)$. Individual changes in trabecular bone volume also correlated well with maximum changes in ${ }^{47} \mathrm{Ca}$-accretion rate. The regression line was described by the equation: $Y=0.97 x-1.62 \pm 6.07$ ( $t=$ $3.9, \mathrm{p}<0.01, \mathrm{r}=0.81)$. These results strongly suggest that the size of the improvement in trabecular bone volume is somehow related to the size of the maximum change in ${ }^{47} \mathrm{Ca}$-accretion rate. Further work is planned to test whether measurement of the accretion rate provides a useful indicator for titrating an effective dose in individual patients.

Despite the encouraging changes in trabecular bone, cortical bone density did not show comparable increases. Furthermore, the balance studies showed no net retention of calcium or phosphate, although the pronounced increases in trabecular bone would have consumed an average of at least $12 \mathrm{mmol}$ calcium $/ 24 \mathrm{~h}(481 \mathrm{mg} / 24 \mathrm{~h})$ over six months. These data suggest that the observed increases in trabecular bone were partly at the expense of cortical bone, and some supporting evidence for this is provided by studies on a subgroup of eight patients whose bone density was measured more often than that in the others and in whom changes in calcium balance correlated closely with changes in bone density in the distal femur (Hesp et al, unpublished observations). The adverse trend in cortical bone density associated with treatment, however, was small and could account for only a minor part of the increase in trabecular bone.

The implications of this study for treatment are intriguing since the only other treatments so far shown to have increased trabecular bone volume in osteoporosis used sodium fluoride in doses associated with a high incidence of side effects. ${ }^{19} 20$ Compared with our results in rats, ${ }^{21}$ the failure of human parathyroid hormone fragment to increase dietary calcium absorption was surprising and may have limited the ability of our patients to increase cortical bone mass. Perhaps the increases in plasma concentration of hormone fragment associated with our mode of administration were so brief that the renal $1 \alpha-$ hydroxylase responsible for 1,25-dihydroxycholecalciferol synthesis was not stimulated. ${ }^{22}$

Calcium and phosphate retention could perhaps be enhanced (by taking advantage of the temporal relation in the normal physiology of Frost's "basic multicellular unit") ${ }^{23}$ with a regimen in which treatment is cyclically interrupted so that the prolonged period of osteoblastic activity after each period of activation is unopposed by excess osteoclasts. Alternatively this hormone fragment might best be used in combination with oestrogen, calcitonin, a diphosphonate, or some other agent that will limit resorption while allowing bone formation to continue. We are currently investigating several of these possibilities.

We acknowledge the clinical and scientific help of many colleagues, particularly Dr J M Zanelli who screened the patients' sera for antibodies, and Dr N Veall and Professor R Hoffenburg for their initial encouragement and help with the design of the study. We thank our many colleagues who helped in providing technical, nursing, and dietetic services, particularly Mr D Gray, Mr J R Green, and Mrs C Benney.

Requests for reprints to $\mathrm{Dr} J$ Reeve, MRC Clinical Research Centre, Harrow, Middlesex HA1 3UJ.

\section{References}

${ }^{1}$ Marshall JH, Liniecki J, Lloyd EL, et al. Alkaline earth metabolism in adult man. Health Phys 1973;24:125-221.

2 Reeve J, Hesp R, Wootton R. A new tracer method for the estimation of rates of bone formation and breakdown in man. Calcif Tissue Res 1977 ;22, suppl:311-3.

${ }^{3}$ Cohn SH, Ellis KJ, Wallach S, Zanzi I, Atkins HL, Aloia JF. Absolute and relative deficit in total skeletal calcium and radial bone mineral in osteoporosis. F Nucl Med Allied Sci 1974;15:428-35.

4 Reeve J, Hesp R, Williams D, et al. The anabolic effect of low doses of human parathyroid hormone fragment on the skeleton in postmenopausal osteoporosis. Lancet 1976 ; 1 :1035-8.

5 Parsons JA, Bernat M, Bijvoet OLM, et al. Low doses of a synthetic fragment of human parathyroid hormone (hPTH 1-34) as a stimulus to bone formation. In: Barzel US, ed. Osteoporosis II. New York: Grune and Stratton, 1979:151-9.

${ }^{6}$ Reeve J, Tregear GW, Parsons JA. Preliminary trial of low doses of human parathyroid hormone 1-34 peptide in treatment of osteoporosis. Calcif Tissue Res $1976 ; 21$, suppl:469-77.

7 Reeve J, Wootton R, Hesp R. A new method for calculating the accretion rate of bone calcium and some observations on the suitability of strontium-85 as a tracer for bone calcium. Calcif Tissue Res 1976; 20:121-35.

${ }^{8}$ Meunier PJ, Bianchi GS, Edouard CM, Bernard JC, Courpron P, Vignon GE. Bony manifestations of thyrotoxicosis. Ortho Clin North Am 1972;3:745-74.

- Schenk RK, Merz WA, Müller J. A quantitative histological study on bone resorption in human cancellous bone. Acta Anat (Basel) 1969; $74: 44-53$.

10 Matrajt H, Bordier P, Martin J, Hioco D. Technique pour l'inclusion des biopsies osseuse non décalcifiées. Fournal de Microscopie 1967;6: 499-504. 
${ }^{11}$ Meunier PJ, Courpron P, Edouard C, Bernard J, Bringuier J, Vignon G Physiological senile involution and pathological rarefaction of bone. Clin Endocrinol Metab 1973;2:239-56.

12 Meunier PJ, Edouard C, Courpron P, Toussaint F. Morphometric analysis of osteoid in iliac trabecular bone. Methodology: dynamic significance of the osteoid parameters. In: Norman AW, et al, eds. Vitamin $D$ and problems related to uraemic bone disease. New York Walter de Gruyter, 1975:149-55.

13 Parsons JA, Reit B, Robinson CJ. A bioassay for parathyroid hormone using chicks. Endocrinology $1972 ; 92: 454-62$.

${ }^{14}$ Cameron JR, Sorenson J. Measurement of bone mineral in vivo: an improved method. Science $1963 ; 142: 230-2$.

15 West RR, Reed GW. The measurement of bone mineral in vivo by photon beam scanning. Br $\mathcal{F}$ Radiol $1970 ; 43$ :886-93.

${ }^{16}$ Bell GH, Dunbar O, Beck JS. Variations in strength of vertebrae with age and their relation to osteoporosis. Calcif Tissue Res 1967;1:75-86.

17 Boyce BF, Courpron P, Meunier PJ. Amount of bone in osteoporosis and physiological senile osteopenia: comparison of two histomorphometric parameters. Metabolic Bone Disease and Related Research 1978;1: $35-8$.
18 Elsasser U, Hesp R, Klenerman L, Reeve J, Veall N, Wootton R. Deficit of trabecular and cortical bone in the radius in low-turnover osteoporosis. Clin Sci Mol Med 1979;57:22p.

19 Parsons V, Mitchell CJ, Reeve J, Hesp R. The use of sodium fluoride, vitamin $\mathrm{D}$ and calcium supplements in the treatment of patients with axial osteoporosis. Calcif Tissue Res 1977;22, suppl:236-40.

${ }^{20}$ Meunier PJ, Bressot C, Vignon E, et al. Radiological and histological evolution of post-menopausal osteoporosis treated with sodium fluoridevitamin D-calcium. Preliminary results. II CEMO symposium, Geneva Médecine et Hygiène 1978:263-76.

21 Parsons JA, Zanelli JM, Gray D, et al. Double isotope estimates of in testinal calcium absorption in rats: enhancement by parathyroid hormone and 1,25 dihydroxycholecalciferol. Calcif Tissue Res 1977 22, suppl:127-32.

22 Bilezikian JP, Canfield RE, Jacobs TP, et al. Response of $1 \propto, 25$ dihydroxyvitamin $\mathrm{D}_{3}$ to hypocalcemia in human subjects. $N$ Engl $\mathcal{f}$ Med $1978 ; 299: 437-41$.

${ }^{23}$ Frost HM. Tetracycline-based histological analysis of bone remodelling. Calcif Tissue Res 1970;3:211-37.

(Accepted 7 February 1980)

\title{
Effect of propranolol and metoprolol on parathyroid hormone and calcitonin secretions in uraemic patients
}

\author{
B COEVOET, C DESPLAN, J L SEBERT, R MAKDASSI, M ANDREJAK, J D GHEERBRANT, \\ M TOLANI, C CALMETTE, M S MOUKHTAR, A FOURNIER
}

\section{Summary and conclusions}

Nine uraemic patients not being treated by dialysis received intravenous propranolol $1 \mu \mathrm{g} / \mathrm{kg} / \mathrm{min}$ for 85 minutes after a priming dose of $1 \mathrm{mg}$. Fifteen days later, six of them received intravenous metoprolol $1.2 \mu \mathrm{g} / \mathrm{kg} /$ min after a priming dose of $1.2 \mathrm{mg}$. Plasma concentrations of parathyroid hormone (PTH) and calcitonin fell significantly after propranolol but not after metoprolol, whereas no change in plasma concentrations of ionised calcium and phosphate occurred with either drug. Heart rate fell similarly with both drugs.

The fact that propranolol acutely suppressed PTH and calcitonin secretion in uraemic patients indicates that further studies are warranted to assess the long-term effects of the drug on the secretion of these hormones and on renal osteodystrophy. The contrast between the responses to propranolol and metoprolol supports the concept that PTH and calcitonin secretion is modulated through specific beta ${ }_{2}$-receptors.

\footnotetext{
Service de Néphrologie-Hémodialyse, Centre Hospitalier Regional et Universitaire d'Amiens, Amiens, France

B COEVOET, MD, physician

J L SEBERT, MD, physician

R MAKDASSI, MD, physician

$M$ ANDREJAK, MD, physician

A FOURNIER, MD, physician

$\mathrm{J} D$ GHEERBRANT, $M D$, physician

$M$ TOLANI, $M D$, physician

Unité Inserm U113, Paris, France

C CALMETTE, MD, physician

M S MOUKHTAR, MD, physician

C DESPLAN, PHD, scientist
}

\section{Introduction}

Most uraemic patients suffer from two potentially serious complications: hypertension and renal osteodystrophy. In about $20 \%$ of the hypertensive patients the hypertension persists despite ultrafiltration and they need antihypertensive drugs. ${ }^{1}$ Renal osteodystrophy in patients on long-term haemodialysis is caused mainly by osteitis fibrosa secondary to parathyroid hormone (PTH) hypersecretion. ${ }^{2}$ Insufficient secretion of calcitonin has, however, also been incriminated. ${ }^{\text {s }}$

Interactions between $\beta$-adrenergic receptors and secretion of PTH and calcitonin have been shown. For example, in-vitro studies with radioactive hydroxybenzylpindolol ${ }^{4}$ have clearly shown the existence of $\beta$-adrenergic receptors in the parathyroid tissue. Furthermore, the fact that isoprenaline had a greater effect in stimulating PTH and adenosine monophosphate secretion than epinephrine and epinephrine a greater effect than norepinephrine suggests that these receptors are of $\beta_{2}$ type. Finally, propranolol has been shown to prevent the increase of PTH secretion by catecholamines but not the increase induced by hypocalcaemia. The results of these in-vitro studies have been confirmed by in-vivo studies in animals, ${ }^{5}{ }^{6}$ but studies in man have given inconsistent results. ${ }^{7-12}$

Direct evidence of the interaction of $\beta_{2}$-adrenergic receptors and calcitonin secretion has not been produced, but isoprenaline, epinephrine, and salbutamol have been shown to stimulate calcitonin secretion and propranolol to block it in vitro ${ }^{13}$ and in animals $^{1415}$ and normal men. ${ }^{16}{ }^{17}$ In uraemic patients Heynen et $a l^{17}$ have shown that propranolol can prevent the increase of calcitonin secretion induced by alcohol ingestion.

The data in man are therefore contradictory and concern only propranolol and not the newer cardioselective beta-blockers. Because these newer drugs may offer advantages over nonselective drugs (shorter titration duration, less frequent hypoglycaemia on dialysis, and less bronchoconstriction ${ }^{18}$ ) their use is increasingly being considered in the treatment of hypertension in uraemic men. Since uraemic patients also have a secondary hyperparathyroidism the effects of these two types of betablockers on their PTH and calcitonin secretion may be relevant 